\title{
"Velhos são os Trapos": do positivismo clássico à nova era
}

"Aged People are Rags": from classic positivism to the new era

\section{Carlos António Laranjeira}

Licenciado em Enfermagem. Doutor em Ciências de Enfermagem. Professor Adjunto da Escola Superior de Saúde do Campus Universitário Jean Piaget de Viseu, Portugal.

Endereço: Estrada do Alto do Gaio, Galifonge, CEP 3515-776, Lordosa, Viseu, Portugal.

E-mail: carlos.brightmanळgmail.com

\section{Resumo}

Para que o ser humano consiga concretizar o direito à vida plena e digna, para que se justifique completamente a procura pela longevidade, deve socialmente permitir-se que essa vida maior seja igualmente melhor. Para que isso aconteça algo tem que mudar nas representações da velhice, no respeito pelas particularidades que a envolvem e pela oferta de estruturas específicas. A velhice é uma fase da vida que tem sido socialmente desvalorizada, negativamente representada, o que se reflete na qualidade de vida dos idosos. Esse ensaio reflexivo pretende desvelar os principais debates culturais sobre a velhice, ao analisar duas estruturas ideológicas dicotômicas sobre o envelhecimento e a velhice. Os resultados são defensores da necessidade de construção de imagens positivas sobre o envelhecimento, para combater os tradicionais modelos de declínio e de despessoalização. Realça-se a complexidade e a heterogeneidade dos fenômenos em análise sublinhando a aplicação de novas estratégias destinadas à construção de uma nova era sobre a velhice, ancorada nos paradigmas de cidadania e pluralidade sociais.

Palavras-chave: Vulnerabilidade; Senescência; Velhice; Qualidade de vida; Exclusão social. 


\section{Abstract}

For human beings to fulfil their right to live a full and dignified life, to completely justify the quest for longevity, it must be socially possible for that greater life to be also a better one. For this to occur, something needs to change in the representations of old age, in the respect for its particularities, and in the supply of specific structures. Old age is a stage of life that has been socially devalued, being represented in a negative way. This reflects on the quality of life of older people. This reflexive essay shall explore the main cultural debates regarding old age by analysing two dichotomic ideological structures on aging and old age. The results defend the need to build positive images regarding aging in order to fight the traditional models of decline and depersonalization. Noteworthy is the complexity and heterogeneity of the phenomena being analysed, highlighting the application of new strategies in order to build a new era for old age anchored on the social paradigms of citizenship and plurality. Keywords: Vulnerability; Senescence; Old Age; Quality of Life; Social Exclusion.

\section{Introdução}

Na memória do pensamento europeu, a velhice tem sido um recurso útil para reflectir sobre a condição humana. Antes de Platão, o pensamento filosófico dado à velhice apresentava a propensão para ser predominantemente pessimista, na medida em que a observação dos seus efeitos negativos, não era acompanhada pela exortação em viver esse período da melhor forma possível. Porém os escritos de Cícero permitiram refutar os pontos de vista correntes contra a velhice afirmando que esta depende mais do carácter e do comportamento de cada um do que de circunstâncias externas (Powell, 1988).

Reconhecer essa diversidade constitui o primeiro passo para abordar o tema dos valores sociais da velhice. É nesta perspectiva que poderemos fazer duas considerações. Em primeiro lugar, a idade, como tema cultural assume-se como importante interlocutor para a construção e a decifração de mundos culturais. Em segundo lugar, as concepções conflitantes dependem e são influenciadas por dinâmicas sociais e por estruturas de pensamento específicas a cada contexto. Daqui decorre a possibilidade de considerar a idade um sistema de significados e interpretações sobre o mundo social.

O tema idade dever ser contextualizado e relacionado com princípios de organização social e cultural, tais como a noção de pessoa, de tempo, gênero, morte, curso de vida. Tal esforço permite desvelar os principais debates culturais sobre a velhice. Esses debates não podem ser vistos como práticas classificatórias, porque o discurso sobre a velhice tem operado como um enquadramento para que certos temas, conflitos e tensões do mundo social se possam desenrolar.

Este ensaio reflexivo pretende conhecer e analisar as duas construções ideológicas conflitantes sobre o envelhecimento e a velhice. Em primeiro lugar, refletimos sobre os valores associados ao que tem sido denominado por ageism. A expressão ageism deriva do vocábulo inglês age (idade) e designa os processos sociais de marginalização e de construção de estereótipos pejorativos sobre a população idosa. A esta ideologia contrapor-se-á a ideologia do envelhecimento ativo, adoptada pela Organização Mundial de Saúde (OMS) nos finais da década 
de 1990, que designa o processo de otimização das oportunidades de vida, em termos de saúde, de participação e de desenvolvimento multidimensional da pessoa, à medida que esta envelhece.

\section{Exclusão Social do Idoso}

A emergência de uma visão eminentemente negativa sobre o envelhecimento e a velhice poderá ser analisada a dois níveis: ao nível social, focando as transformações sociais geradas na modernidade e que motivaram um reposicionamento dos mais velhos no seio das relações de poder e autoridade; e ao nível epistémico, ou seja, da produção de conhecimento e, consequentemente, da própria construção da realidade. Nesse segundo nível, é possível salientar dois processos: a construção da velhice como objeto de olhar científico e sua conceitualização ideológica, isto é, a formação de ideias, imagens e associações que moldaram profundamente a visão sobre ela.

No que concerne ao primeiro nível, a investigação sobre a problemática da velhice tem-se revelado cada vez mais pertinente no contexto das sociedades ocidentais, na medida em que estas apresentam significativas dinâmicas de envelhecimento populacional. Face a esse cenário, a proliferação de estudos, sobretudo de cariz sociológico, tende a questionar diretamente o impacto do modelo de modernização na modulação de concepções vigentes sobre envelhecimento e velhice.

Até há bem pouco tempo acreditava-se que existia uma espécie de "Golden Age" na terceira idade, a qual coexistia com várias gerações numa família extensa. Nessas famílias, os idosos seriam venerados e respeitados. Parece, então, que se evoluíra de um período em que os idosos desempenhavam um papel social e familiarmente útil, para um tempo em que a terceira idade passara a ser desprezada e cada vez mais votada ao isolamento social (Wolf e Pillemer, 1989).

Uma das vantagens da perspectiva adotada na definição de exclusão social está no fato de permitir analisar nessa perspectiva (de exclusão) o problema social dos idosos, certamente um dos mais graves problemas sociais da sociedade em geral. A expres- são “exclusão social” pertence à perspectiva própria da tradição francesa na análise de pessoas e grupos desfavorecidos. Castel (1990), uma das principais referências nesta matéria, define "exclusão social" como a fase extrema do processo de marginalização, entendido esse como um percurso descendente, ao longo do qual se verificam sucessivas rupturas na relação do indivíduo com a sociedade. São inúmeros os processos que, em conjunto, ajudam a compreender a emergência de uma visão negativa sobre o envelhecimento e a velhice. Desses processos, destacam-se, a título de exemplo, a industrialização, a modificação dos modelos de família, a institucionalização da reforma, a desmistificação das imagens do idoso como guardião da sabedoria ancestral, a educação de massas e o ritmo desenfreado do tecnocratismo, entre outros. 0 declínio do estatuto dos idosos é reflexo da secularização do poder nas dinâmicas sociais.

Hareven (1995), demonstra que, a partir dos finais do século XIX, o envelhecimento começou a ser formalizado como um período de declínio e de obsolescência. De fato, nesse contexto, surgiram diversos estudos que procuram determinar a relação entre envelhecimento e eficiência, os quais conduziram a comparações negativas entre juventude e velhice ${ }^{1}$.

A partir dessa altura, a velhice deixa de ser predominantemente encarada como parte especial, mas integrante do curso de vida e, portanto, inolvidável, passando a ser demarcada como um período distinto, caracterizado pela senescência. Consequentemente a visão de velhice é marcada como condição de dependência, tanto física como mental (Katz, 1995). Incapacidade funcional, fragilidade, morbilidade, são termos comumente usados para identificar a vulnerabilidade dos idosos. Diversos estudos realizados (Fired e Guralnik, 1997; Fried e col., 2001) verificaram que a incidência da incapacidade funcional aumenta com a idade, situação que indica a necessidade de intervenções apropriadas pelos profissionais de saúde, numa ruptura com uma assistência prestada de forma fragmentada. Todavia essa reconceitualização promoveu um processo de medicalização da velhice. Desta feita, conceitos

1 Em 1874, por exemplo, George Beard procurou identificar limites que a velhice impunha ao nível das faculdades mentais. 
como o de vitalidade, esperança de vida e longevidade deixaram de depender da disciplina individual e passaram a depender dos avanços inescapáveis da genética. Os progressos no conhecimento do genoma humano e os avanços da engenharia genética abriram, em finais do século XX, uma nova perspectiva à medicina humana: a medicina preditiva, que permite conhecer cada indivíduo e, muito precocemente, os fatores de risco genômicos que poderão ameaçar sua vida (Sournia e Ruffie, 1986). Nesse âmbito, alguns autores têm chamado a atenção para o alegado «patrocínio» da doença pela indústria farmacêutica: através de campanhas dirigidas para o público em geral, e para os idosos em particular (Moynihan e col., 2002). A estratégia usada seria o marketing do medo, que se traduz pela sobrestimação de situações clínicas e fatores de risco na população e pela "medicalização” de situações fisiológicas. Dessa forma, a publicidade farmacêutica contribui para a difusão de novas categorias de doenças e para a medicalização da vida diária (Cathebras, 2003). Diante desse cenário, torna-se emergente o conceito de prevenção quaternária, o nível mais elevado de prevenção em saúde, o qual pretende evitar o excesso de intervencionismo médico através da detecção de indivíduos em risco de sobretratamento - trata-se pois de uma prevenção da iatrogenia. Isso implica não só a prescrição criteriosa e economicamente racional de métodos diagnósticos e terapêuticos pelos clínicos, mas também a capacitação dos idosos/consumidores de cuidados de saúde, visando a procura apropriada dos cuidados de saúde e o conhecimento das vantagens e inconvenientes (Moynihan e col., 2002).

Vale a pena fazer aqui um parêntese para enunciar as ideias sobre a velhice que predominavam no período renascentista e assim melhor avaliar a ruptura verificada no século XIX e, nomeadamente na viragem do século XX, no qual se assiste a uma crescente medicalização da velhice.

As ideias renascentistas gravitavam em torno de ideais universalistas de natureza humana fortemente influenciados pela antiguidade clássica. Montaigne (1991) ao postular a indissociabilidade entre corpo e alma, remete para a necessidade de um equilíbrio entre ambos, trata-se de uma concepção inovadora que nos fala da possibilidade de sentirmos e pensarmos também através do corpo. Todavia essa visão acaba por refutar a possibilidade do acréscimo de expertise (sabedoria) e prestígio social poderem compensar as perdas sofridas na velhice.

Com a medicalização da velhice no século XIX, houve uma ruptura dos valores renascentistas, na medida em que o conceito de longevidade da vida humana deixou de ser um fato médico-filosófico e passou a ser uma certeza clínica-biológica (Katz, 1995). À definição clínica de velhice, sobreveio a atribuição de características sociais e psicológicas ao idoso, estando estas últimas ligadas aos condicionalismos do foro biológico impostos pelo envelhecimento. Essa tendência manifestou-se no pensamento de vários autores da época. Comte interpretava o prolongamento excessivo da duração média de vida de uma geração como uma força de bloqueio do progresso. Essa visão positivista, reforça ideias e analogias atribuídas à velhice, tais como o conservadorismo, a perda de autonomia ou capacidade deliberativa sobre si próprio, a incapacidade funcional e a infantilização (Hockey e James, 1995).

Assumindo-se que a velhice transporta consigo algumas fragilidades, físicas e sociais, a violência para com o idoso surge como incompreensível. Numa tentativa de perceber o que gera o maltrato do idoso vão surgindo várias propostas de leitura e explicação para essa problemática. Falar de maltrato do idoso implica falar das representações sociais e das estruturas de suporte à velhice. O idoso é infantilizado, diminuído ao ser adjetivado como senil, decrépito, etc. A pobreza e a idade estão socialmente muito associadas e contribuem massivamente para os estereótipos que relacionam velhice com inutilidade, invalidez e doença (Decalmer e Glendenning, 1997).

Wolf e McCarthy (1991), através de uma análise comparativa de vários tipos de maltrato (físico, psicológico, financeiro, negligência ativa e passiva), conseguiram identificar, pelo menos, três perfis distintos dos idosos vítimas de violência e dos seus agressores. Assim, um primeiro perfil diz respeito às vítimas de maltrato físico e psicológico. Estas, apesar de serem relativamente independentes nas suas atividades diárias sofrem, no entanto, de problemas emocionais. Nesse caso, os agressores têm geralmente uma história de alcoolismo e/ou doença mental, vivem com a vítima e dependem dela financeiramente. Um segundo perfil refere-se às vítimas 
de negligência que são em geral muito idosas, sofrem de incapacidade mental e física e têm pouco apoio social. Estes representam para as pessoas que cuidam deles, uma fonte de grande desgaste e estresse. Finalmente, um terceiro perfil diz respeito às vítimas de abuso material ou financeiro, as quais tendem a ser solteiras e com contatos sociais e redes de apoio muito limitados. Por sua vez, seus agressores têm problemas financeiros e, frequentemente, uma história de abuso de drogas e de álcool.

Assim uma visão de síntese parece mostrar-nos claramente que a qualidade de vida dos idosos ou a velhice pautada pela violência e pelo mal-estar não se regem pelas características do envelhecimento.

Torna-se atualmente necessário centrarmo-nos nas formas pelas quais o idoso como ator social, se (re)posiciona de modo contingente em relação ao ethos cultural dominante. Com esse ethos cultural queremos designar a constelação de valores essencialmente moral que norteia a visão do mundo numa dada realidade social e em determinado contexto histórico.

Esse objetivo é conseguido pela redefinição positiva do envelhecimento e da velhice.

\section{Envelhecimento Ativo}

O recente protagonismo da população mais velha parece constituir para diversos autores um indicador da passagem de concepções obscurantistas sobre o envelhecimento e a velhice para uma suposta nova era do envelhecimento capaz de evocar imagens específicas de vitalidade, atividade e empreendedorismo. Para Gergen e Gergen (2000) a emergência dessa nova era é explicada através de três fatores: representatividade da população idosa, resultante do envelhecimento populacional, as novas oportunidades de vida, resultantes das novas tecnologias da comunicação e, por fim, uma melhoria significativa da situação econômica desse segmento populacional.

Para a antropologia, sendo a cultura uma matriz que articula dimensões simbólicas e práticas socioculturais, uma das características da humanidade será o de criar, atribuir e reproduzir, de forma sistemática racional e estruturada, significados e sentidos “às coisas do mundo". São esses fenôme- nos que permitem concretizar ancoragens e definir identidades socioculturais. Com o aumento do envelhecimento demográfico, existe a necessidade de capacitação (empowerment) dos idosos e das comunidades, para a criação de ambientes favoráveis à saúde e do desenvolvimento de aptidões pessoais (educação para a saúde). Aqui, novos conceitos de autonomia, envolvimento, participação, entre outros pilares do ethos novo, são centrais, pela centralidade do corpo nos processos de construção identitária e das imagens sobre envelhecimento, dos quais se destaca a cirurgia estética, capaz de alargar os conceitos de sensualidade e beleza (Featherstone e Hepworth, 1996). 0 envelhecimento passa a ser um processo em aberto, negociável que pode ser retardado.

A redescrição do envelhecimento deverá igualmente passar pelas dimensões mentais, comportamentais e relacionais. Se é habitual falar da força psicológica nas crianças (Fonagy e col., 1994; Fonagy, 2001), pode-se questionar o que isso poderá significar no idoso; em outras palavras, poder-se-á falar de resiliência e velhice?

A perda da utilidade social e a doença podem ocasionar perturbações graves nos idosos. Assim, o envelhecimento poderia ser considerado um contexto de risco, porém os idosos reagem de formas muito diferentes (Whitbourne, 2001). Alguns parecem desenvolver um comportamento que facilmente pode ser classificável como resiliente, no qual os acontecimentos normais e esperados de vida são, sobretudo, precipitantes de novas expressividades em vez de ameaças à continuidade do self (Sullivan e Fisher, 1994).

O desafio consiste em encontrar formas que possibilitem a emancipação dos indivíduos, recolocando-os em arenas sociais significativas, seja mediante o trabalho - através de uma segunda carreira - seja através do voluntariado e/ou ativismo. Emerge o conceito de empreendedorismo proposto por Hisrich e Peters (2004) como o processo de criar algo novo que surja como valor acrescentado, presumindo geralmente dedicação em tempo e esforço, capacidade de aceitar correr riscos financeiros, psíquicos e sociais, mas também clarividência para perceber que podem surgir importantes recompensas em nível de autonomia, satisfação profissional e independência econômica. 
Finalmente surge a visão epicurista do envelhecimento pela valorização do prazer, no qual se recupera o conceito helênico de heroísmo. 0 denominado turismo sênior parece ilustrar com especial vivacidade esse modelo, ao proporcionar novas possibilidades de vivenciar o envelhecimento.

Apesar de seus limites essas diferentes visões contribuem para a desconstrução das imagens negativas do envelhecimento e da velhice, o que permeia os principais objetivos da gerontologia social. Essa reorientação foi politicamente reafirmada pela Organização das Nações Unidas em 1999, o ano internacional das pessoas idosas. Nesse âmbito foram materializados vários princípios: o da dignidade, o da autonomia, o do desenvolvimento pessoal, o do acesso aos cuidados básicos e por fim o da participação ativa na sociedade. Todos esses princípios deverão estar fundamentados nos domínios da cidadania, da emancipação e da pluralidade.

\section{(Re)inventar Identidades}

Os idosos encenam a vida em sociedade como os restantes atores sociais que a constituem, a não ser na medida em que estão perigosamente na iminência de se destituírem dos seus papéis de atores para passarem aos de espectadores.

É contra isso que surgem as Universidades de Terceira Idade com suas práticas andragógicas, capazes de reconhecer a experiência dos idosos quantitativa (anos de vida) e qualitativa (diversidade de papéis e de contextos de existência) muito diferente da dos jovens, o que de resto trás consequências positivas, mas também negativas. Consequências positivas: por um lado os idosos são fonte de recursos, suas experiências constituem "matéria" da própria aprendizagem, enriquecida, por exemplo, através de discussões de grupo, exercícios de simulação, trabalho de campo, resolução de problemas; por outro lado, a heterogeneidade das experiências dos idosos reforça a necessidade de planos de formação individualizados e legitima "contratos de aprendizagem" personalizados. Consequências negativas: por um lado, as que decorrem do "avivar" das experiências escolares anteriores, eventualmente não muito gratificantes e, com idosos pouco escolarizados, com certeza muito autopenalizantes; por outro lado, a emergência de modos habituais de pensar e de agir, de preconceitos, de defensividades.

Na perspectiva andragógica, as experiências dos aprendentes não pode ser ignorada, desvalorizada, minimizada, rejeitada, porque isso implicaria rejeitar a própria pessoa, sobretudo quando se está diante de um idoso pouco escolarizado, no limite um analfabeto, por exemplo, tudo o que muitas vezes “tem”, faz valer e funda a sua dignidade é a sua experiência de vida.

Mais do que os conteúdos das aulas, aquilo que é realmente valorizado são os momentos, os espaços, que servem como ponto de partida para o estabelecimento de relações (novas sociabilidades) em um registro identificado como o imaginário acadêmico, o qual permite aos indivíduos distanciarem-se de imagens negativas, cumprindo assim um dos postulados preconizados pelo envelhecimento ativo: a atividade e o desenvolvimento intelectual.

Trata-se de um novo trabalho cultural de produção identitária que inserido na era do envelhecimento ativo se torna, por isso, uma solução biográfica do idoso diante da ameaça de despessoalização.

\section{Contexto Português}

Ao analisar o lugar do idoso na sociedade, fenômeno que até há pouco passava despercebido à opinião pública em geral, o envelhecimento é hoje apontado, com relativa frequência, como uma dos aspectos a ter em conta na definição das políticas de médio e longo prazo. No caso português, deve acrescentar-se que também para políticas de curto prazo e, em alguns aspectos, mesmo para medidas urgentes, fala-se em três tipos de envelhecimento: envelhecimento individual, devido à longevidade; envelhecimento populacional, no sentido de que existem mais pessoas nos grupos de idade mais elevada; envelhecimento ativo, associado ao início mais tardio da vida ativa e às reformas precoces. Os dois tipos que mais diretamente interessam a esta reflexão são o envelhecimento individual e o envelhecimento da população. Resumidamente, esses dois tipos de envelhecimento dizem-nos que as pessoas vivem mais tempo, o que quer dizer que a "velhice" é menos definida pela idade do que pelas faculdades e capacidades pessoais, ao passo que o 
segundo sublinha que a população idosa é cada vez mais numerosa e, portanto, não poderá ser encarada como se tratasse de um grupo "residual". Segundo Carrilho (1993) a população com mais de 6o anos de idade representava 14,4\% da população em 1970 e passará a representar $23,4 \%$ em 2010. No mesmo período, a proporção da população com mais de 65 anos passará de 9,7\% para 17,6\%. Em outras palavras, a população idosa é uma parte cada vez mais significativa da população total.

Daqui se conclui que um dos critérios pelo qual se terá de avaliar o grau de "humanidade" da sociedade é o do lugar e do papel que reserva aos idosos na vida social. 0 que se verifica abona pouco a favor desse humanismo. Quer a sociedade quer o quotidiano das pessoas estão organizados de tal modo que os idosos não têm lugar nem papel na vida social. Nos casos extremos, que infelizmente não são raros entre nós, essa exclusão social pode tomar a forma de total solidão. É uma forma de exclusão social e de privação que pode não ter qualquer relação com a falta de recursos e, portanto, com a pobreza, embora possa coexistir com ela.

Essa exclusão verifica-se, antes do mais, ao nível familiar. Abandonado que foi o modelo da família alargada, em que conviviam coabitando pelo menos três gerações, passou-se para o da família nuclear, composta de duas gerações (pais e filhos). 0 estilo de vida atualmente predominante fragmentou até a família nuclear, tornando por vezes difícil a possibilidade diária de pais e filhos se encontrarem e conviverem, trata-se de um estilo em que o idoso não cabe, não tem lugar.

As soluções mais frequentes vão na linha dos "lares para idosos", e de algumas formas de ocupação do tempo, tais como os "centros de dia para idosos", as "colónias de férias para idosos", enfim o turismo para idosos. Quanto a essas atividades, é de notar que elas tendem a agravar a "ghetização" dos idosos, ao desintegrá-los do resto da sociedade. Pondo-os a conviverem entre si, poderão atenuar a solidão, mas não proporcionam a possibilidade de conviverem com outras idades, como é próprio da vida. Dessa forma, subsiste um problema central: uma sociedade que tenha de lançar mão de lares para idosos, por melhores que sejam, revela desrespeito pelo passado e desumanidade para com o presente. Impõe-se que tenhamos consciência de que ninguém nasceu para viver num lar, e que teremos as consequências desse fato. Os principais caminhos de integração social dos idosos passarão pela família, pelo trabalho e pela comunidade local. Para efeito, é imperioso que as mudanças sociais relacionadas ao mercado de trabalho sejam geridas de modo a facultar aos idosos a possibilidade de exercerem atividades socialmente úteis e compatíveis com suas capacidades, mesmo que não remuneradas. Torna-se um desafio a redução da institucionalização do idoso, potenciando seu regresso ao seio da família, sendo que para isso tenha de contar com apoios financeiros e em serviços. Finalmente a solidariedade da comunidade local poderá ter um papel particularmente importante, quer na oferta e enquadramento de locais de trabalho quer no que respeita à convivialidade no sentido de evitar a estagnação geracional do idoso.

\section{Considerações Finais}

Chegados aqui, inscrevemos a análise que fizemos no domínio da velhice, uma experiência fortemente marcada por contradições ou mesmo por dilemas, na medida em que se dá um confronto entre múltiplas - e por vezes contraditórias - interpretações da vida e do curso de vida, apreendidos pelos atores sociais como formas de problematizar a vida.

Verificamos que a velhice é usada para falar da questão da igualdade da condição humana, e dizer-se que o envelhecimento tem um horário inexorável e paritário, atinge todos e equipara todas as pessoas. Emerge a vertente idiossincrática que nos permite perceber que apesar dos iminentes processos de estigmatização e de despessoalização, é a unicidade de uma identidade renovada que inaugura a concepção do envelhecimento ativo.

\section{Referências}

CARRILHO, M. "O processo de envelhecimento em Portugal : que perspectivas...?”, Revista Estudos Demográficos, Lisboa, n. 31, p. 75-98, 1993.

CASTEL, R. Extreme cases of marginalisation

- from vulnerability to disaffiliation. Paper presented at the Seminar on Poverty, Marginalisation and Social Exclusion in the Europe. Itália, 23 a 25 de abril de 1990. 
CATHEBRAS, P. Le docteur Knock habite Wall

Street: les nouvelles cibles de l'industrie pharmaceutique. La Revue de Médecine Interne, Issy-les-Moulineaux, v .24, n. 8, p. 538-541, aug. 2003.

DECALMER, P.; GLENDENNING, F. The mistreatment of the elderly people. London: Sage Publications, 1997.

FEATHERSTONE, M.; HEPWORTH, M. The mask of ageing and the post-modern life. In: FEATHERSTONE, M.; HEPWORTH, M.; TURNER, B. S. (ed.) The Body: social process and culture theory. London: Sage Publications, 1996. p. 371389.

FIRED, L. P.; GURALNIK, J. M. Disability in older adults: evidence regarding significance, etiology, and risk. Journal of the American Geriatrics Society, New York, v. 45, n. 1, p.92-10o, jan. 1997.

FRIED L. P. et al. Frailty in older adults: evidence for a phenotype. The journals of gerontology. Series A, Biological sciences and medical sciences, Washington, DC, v. 56, n. 3, p.146-156, mar. 2001.

FONAGY, P. et al. The Emanuel Miller Memorial Lecture 1992. The theory and practice of resilience. Journal of child psychology and psychiatry, and allied disciplines, London, v. 35, n. 2, p.231-257, feb. 1994.

FONAGY, P. Développement de la psychopathologie de l'enfance à l'âge adulte : le mystérieux déploiement des troubles dans le temps. $L a$ Psychiatrie de l'enfant, Boulogne-Billancourt, France, v. 44, n. 2, p. 333-369, 2001.

GERGEN, K.; GERGEN, M. The new aging: self construction and social values. In: SHAIE, K. Warner; HENDRICKS, Jon (ed.). The evolution of the aging self: the societal impact of aging process. New York: Springer Publishing Company, 2000. p. 281-306.

HAREVEN, T. Changing images of aging and the social construction of the life course. In: FEATHERSTONE, Mike; WERNICK, Andrew (ed.). Images of Aging: cultural representations of later life. London: Routledge, 1995. p. 119-134.
HISRICH, R.; PETERS, M. Empreendedorismo. 5 . ed. São Paulo: Bookman, 2004.

HOCKEY, J.; JAMES, A. Back to our futures: imagining second childhood. In FEATHERSTONE, Mike; WERNICK, Andrew (ed.). Images of Aging: cultural representations of later life. London: Routledge, 1995. p. 135-148.

KATZ, S. Imagining the Life-Span: from Miracles to Postmodern Fantasies. In FEATHERSTONE, Mike; WERNICK, Andrew (ed.). Images of Aging: cultural representations of later life. London: Routledge, 1995. p. 61-75.

MONTAIGNE, M. (1580): ensaios. Lisboa: Nova Cultural, 1991.

MOYNIHAN, R.; HEATH, I.; HENRY, D. Selling sickness: the pharmaceutical industry and disease mongering. British Medical Journal, London, v.324, n. 7342, p. 886-89o, april 2002.

POWELL, J. G. F. Cicero Cato Maior de Senectude. Cambridge: University Press, 1988. (Cambridge Classical Texts and Commentaries, 28).

SOURNIA, J.; RUFFIE, J. As epidemias na história do Homem. Lisboa: Edições 70, 1986.

SULLIVAN, W.; FISHER, B. Intervening for success: strengths-based case management and successful aging. Journal of Gerontological Social Work, London, v. 22, n. 1-2, p. 61-74, nov. 1994.

WHITBOURNE, S. Adult development and aging: biopsychosocial perspectives. New York, John Wiley and Sons, 2001.

WOLF, R.; MCCARTHY, E. Elder abuse. In: AMMERMAN, R.; HERSEN, M. (ed.), Case studies in family violence. New York: Plenum Press, 1991. p. 357-377.

WOLF, R.; PILLEMER, K. Helping elderly victims: the reality of elderly abuse. New York: Columbia University Press, 1989.

Recebido em: 15/12/2009

Aprovado em: 28/05/2010 